\title{
The symbols of environmental sustainability in Iranian religious beliefs by emphasizing on Zoroastrianism and Islam
}

Los símbolos de la sostenibilidad ambiental en las creencias religiosas iraníes haciendo énfasis en el Zoroastrismo y el Islam

Author:

Moeine Ossadat Hejazi ${ }^{1, *}$

Behnam Sarbakhshian ${ }^{2}$

\section{SCIENTIFIC RESEARCH}

How to cite this paper:

Hejazi. M. O., Sarbakhshian. B. The symbols of environmental sustainability in Iranian religious beliefs by emphasizing on Zoroastrianism and Islam. North khorasan, Iran. Innovaciencia. 2019; 7 (2): 1-11. DOI: http://dx.doi.org/10.15649/2346075X.760

Reception date:

Received: 28 January 2019

Accepted: 2 May 2019

Published: 25 October 2019

Keywords:

Iranian Culture, Religious Belief, Environmental Sustainability, Symbol.

\section{ABSTRACT}

Environmental issues have always been one of the main axes of sustainable development and the main challenges of the governments. The thing that has caused the most damage to nature is the over-exploitation of man from nature with modernist perspectives. It seems that human beings have a more peaceful, environmentally friendly attitude in the frameworks of traditional views. The two Zoroastrian and Islamic religions have had significant effects on Iranian thought since the beginning of the formation of powerful ancient and historical powers in Iran. Religions have used symbolic languages to express the deep concepts and the induction of internal effects. This study used a descriptive-historical method to identify the symbols related to environmental in indigenous culture and dominant religious beliefs in Iran. The data was collected using documentary research method. The research findings indicate that symbols can be categorized in six major groups including; symbols of sky, wind, and celestial bodies: 1- moon, stars, sun and planets, 2- mountain, soil, rock, cave, desert, 3- water, river, fountains, 4plants: flowers, trees, 5-animals, 6- fire and light. There is a close relationship between Zoroastrian and Islamic beliefs toward elements of nature, in which respect for nature is considered as religious duties. Various symbols have emerged because of these beliefs in Iranian culture that have the ability to capture cultural, literary and artistic realms, sustainable architecture and urbanization on a regional, national, and international scale in order to preserve and restore the environment.

\footnotetext{
Corresponding author: Moeine ossadat Hejazi Email: M.Hejazi@ub.ac.ir

Academic staff of Department of Art and Craft, Faculty of Art, University of Bojnord, North khorasan, Iran

Academic staff of Department of Art and Craft, Faculty of Art, University of Bojnord, North khorasan, Iran.

E-mail: B.Sarbakhshian@ub.ac.ir
} 


\section{INTRODUCTION}

The over-exploitation of environmental resources has caused a serious threat to the destruction of biological species. The continuation of the demolition process will affect future generations hugely. Over the centuries, man has conceived a single spirit in a mutual relationship with nature, and has experienced a peaceful life. By exploring the powers of the new wisdom, one-way communication was formed, and by considering nature as an object, its attitude was based on the level of productivity and economic benefits. This approach was a vulnerability to nature and a serious threat to the environment ${ }^{[1]}$. In modern society, the originality was given to matter. The welfare and growth of financial and economic resources are the ultimate goal of mankind. This attitude has created serious environmental crises for both the current and future generations. Throughout history, nature has always been the source of great forces for mankind. The companionship of man with nature can be identified in the culture and art of any nationality through its symbols and roles. Symbols represent the concrete aspect of human thought and beliefs. Many natural symbols are used in worship, praise and respect for nature and the environment. This is also important in Iranian beliefs and religions. Therefore, the current study seeks to recognize the type of view of the two official religions of Iran, Zoroastrianism and Islam in relation to nature, in order to identify the ideas that sustain the nature in the religions of this land. The study findings can be the basis for raising awareness and moving towards the application of the symbols of the sustainability of nature in the environment.
There is no social and communal life without communication. An important part of the communication process is through symbols. The believers and religious people are linked with a variety of national, religious, cultural and other symbols which by acting on it and receiving a sense of belonging to its symbols, and they will have a unique identity. That is how symbols had significant roles in all primitive, modern, and postmodern societies. In past, concepts were shaped in the human mind instinctively, and his consciousness formulated, construed, conceptualized those concepts as a psychological model, interpreted and defines. But today's civilized man will no longer be able to do this. Essentially, the world around is so crowded that it gives them no opportunity to pay attention to symbols, nor can they interpret them. Today's man is isolated and alone in today's turbulent world because he has lost his nature and lost his unconscious similarity to nature. Thus, in today's civilized society, we see that the role of symbols in human life has diminished, which has caused the destruction of nature and of mankind itself [2]. The main concern of governments today is to achieve sustainability in a way that economic and social improvements can control pollution and environmental damage and maintain and strengthen the human ecosystem. This purpose of this study is to identify the traditional thoughts and beliefs of Iranians during the Zoroastrian and Islamic times as two great official religions throughout the centuries in Iran, as well as the identification and classification of environmental related symbols to achieve the silent cultural capacity to preserve the environment. The study tries to answer the following questions: What were the perspective of the Zoroastrian and Islamic religions toward preserving the environment? What kind of symbolic elements they used to present their perspective to their followers? 
2. THE NATURE VALUE IN THE OFFICIAL RELIGIONS OF IRAN

Considering the values of nature as the mother of life in the planet, there are special symbols, customs and ideologies toward nature in traditional religions. It is expected that there was such an insight in the two great religions of Iran from ancient times, Zoroastrians and Islam. In the following, the views and symbols of these two religions toward nature are discussed.

\subsection{Zoroastrians}

In Zoroastrian viewpoint, man is part of the system of creation, and he is obliged to recognize his position in the world and should have respect for all components of the universe, since they are the origin of Ahura Mazda. Respecting the fire, as one of the manifestations of light in the "fire temple" under the leadership of the Mobad, is the most prominent feature of this ritual. Agricultural, livestock breeding and respecting animal's right are among the things that have been praised by this tradition ${ }^{[3]}$. "Planting trees and farming are ways of worship and" Good deeds "is a tradition of Mazdisna. One of the three Zoroaster sons, called "Artedner", is the first leader of the farmers. In Zoroastrian religious books, treating, nurturing, and respecting livestock and farm animal is recommended. The treatment and cultivation of livestock, however small it may be, and killing vermin is suggested, even if it reduces the punishment of sinners ${ }^{[4]}$. “

In the Zoroastrian religion, the forces of nature were revered and valued. It says in the Yashts (verses of Avesta- Zoroastrian religious book): "We praise all the waters; all the plants. We will salute the mountains from which water is flowing and we salute the lakes and pools and salute the wheat fields." [5] "Herodotus writes that Iranians praise the sun, the moon, the earth, the fire, the water and the wind, and they sacrificed for them ... The water of Lake Urmia, although it was very bitter and salty, was sacred to Zoroastrians.] [5] $»$ In Zoroaster's religion, it is believed that the burning of live trees and branches to heat the oven is a sin and the water droplets of the burning tree will glorify in another world ${ }^{[6]}$. "

The commemoration of the natural elements in the form of celebrations of Nowruz, Yalda, Sadeh, Tirgan and many other great memorials during the months of the year are all for the respect of the elements of nature and its related beliefs. These rituals show the optimistic spirit of loving nature among Iranian in the Mazdisna rituals. One aspect that sustainable development always emphasizes is the maintenance of any capital and resources for future generations. This aspect of the literature of sustainable development is beautifully stated in Zoroastrianism "Praise, admiration, and pleasure for all the Fravashi and inocents; those who are dead and those who are alive and those who are not yet born" [4]. “

\subsection{Islam}

In Islam, man is considered as the representative of God on the planet. After creation of human, Lord said "Congratulation to the best creature" and the human beauty is something beside his beauty in appearance and is more due to his personality. The most important element of the divine caliphate after learning the religious teachings is to build the earth and save it from any kind of deterioration and darkness. The earth stands for the entire range of 
beings. Therefore, environmental culture is mixed with God's succession. Human being as the caliph of the Lord is obligated to refine the air, restoration of the earth, planting seedlings, and cleaning the sea and the desert.

The Holy Qur'an introduces God's creatures in nature as signs and manifestations of His existence. In Quran, Foselat Sura (37th chapter) says: the signs of the Lord are the night, the day, the sun and the moon. All the components of nature are always praising the Lord. (Jomah / 1). The Holy Qur'an explicitly states: "All creatures praise God"(p. 44). Since in Islam view, the components of nature are all living entities that are not only constantly praising God, but are the observers of today and witnesses on the Day of Judgment.

The Prophet (pbuh), referring to Mount Ohod, says: "this mountain is called Ohod, it loves us and we like it back ". These words represent the kindness and deep relationship of the Prophet (pbuh) with nature [8]. In the Holy Qur'an, the nature is serving human, but this does not mean that human beings are free to over-exploit it, but that man must act within the limits of the constraints and conditions of the divine laws, and given that life on earth is temporarily and finally we are returning to Him, we should exploit nature as we need it ${ }^{[9]}$.

\section{EXAMPLES OF THE SYMBOLS OF SUSTAINABLE NATURE IN IRANIAN RELIGIOUS BELIEFS}

In this section, we try to realize the symbols that are related to nature and the environment in Zoroastrianism and Islam, and the human relationship with its environment in the context of Iran's culture and geography before and after Islam.
Therefore, the symbols derived from the nature of the elements are categorized into six groups: sky; wind and celestial bodies, plants; flowers, trees, water; river, spring, beings and animals, mountains; soil, rock, cave, desert and fire.

\subsection{Sky, wind and celestial bodies: the moon, stars, the sun and planets}

According to the ancient Iranian beliefs, at first the sky, then the water and then the earth were created; after that, plants and animals, and man was the sixth creature, and the fire was the seventh and last creation in the narrative of the creation of the world in Zoroastrianism. The sky is an unlimited space that has had the greatest impact on the human environment on the Earth with its best-known and most efficient objects, including the moon, the sun and the wind. The precipitation, which provided much of human demand for water, but more than enough cause flood, and the shortage leads to droughts, the lightning is destructive, and the sun and the warmth of the universe are all located in ski. Today, the overheating of the planet, the ozone layer depletion, the sun's getting cold, are the major issues that scientists have been busy with. The sun has a glorious position in ancient times, in the Zoroastrian and Islam religions. The sun was considered as God, before Zoroaster, but after his emergence it was degraded to Ahuramazda.

Undoubtedly, the sun and its significance, and its similarities to the Izadmehr, which is the god of light, has gradually become equal to the one and the same, and the oath to it is synonymous with the oath to the absolute Lord. What gives the sanctity to sun among the ancient Iranians was not merely its egsistence, but the sunrays and its light; Mitra is 
not the Sun itself; it is a light that removes darkness and brings life with its brightness and warmth and fertilizes the nature. It also removes the devils of sin and impurity, draught and unproductivity from the earth ${ }^{[11]}$. There are various narrations about the creation of the Sun. One of them is, it was born out of the darkness within a cave, or from the rock, or from the inside of the Lilium ${ }^{[12]}$ at Yalda night. The birth of the Mehr (sun) from the rock or the cave, as well as the Lilium, creates a connection between the position of the sun and other physical elements of nature, such as mountain and plants.

The sun has many concepts in Islam. The sun is a source of radiation and a symbol of beauty and perfection. His place in the fourth quarter is the

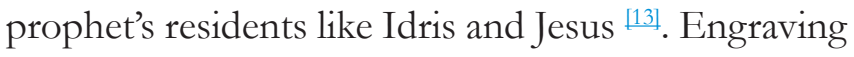
the sun on the gravestones of the Islamic era is a symbol of the continuation of life after death and giving light to the deceased in another world ${ }^{[14]}$.

On the other hand, the moon, like the sun, is the source of inspiration and has a special place in ancient mythology. In ancient Iranian thought, the moon and stars and the sun orbit round the peak of the Hora of the Alborz Range ${ }^{[10]}$. For in the darkness of night it pulls over the curtain of darkness and scandalizes the black demons. According to Bandhashen, the moon is protecting the sprout of beasts and animals, and the first clean and powerful seed was transmitted from the cow's sprout to the moon. In folk culture of many parts of Iran the sun and the moon are husband and wife and they love each other. In mythology, the cause of eclipse is the struggle of mythological gods. The Holy Qur'an has been sworn three times to the moon. Imam Sadiq (a) also referred to some of the benefits of the moon in the well-known hadith of "Tawhid Mufzal" [15].

\subsection{Mountains, soil, rock, cave, desert}

The cone form of the mountains is getting narrower from the slope upwards. The combination of the height and magnitude, the snowcap on the summit peaks and the source of the clear waters, along with the remoteness of most people and animals from its summit to the mountain its relation to humans and many other living things has given a greatness, holiness and mythological stories to it.

In ancient Persia, it was believed that the Earth was originally a flat plate that was wide eastward and westward, and the mountains came out of its surface. In the Avesta, the Alborz was described as the first mountain in the world, when it came out of Earth's surface it took for 800 years. Alborz or Mount Hera was the source of light and water. Vourukasha (a sea in the Avesta) is described as the focal point of water condensation, which is one-third the size of the earth and from south it extends to the Alborz slopes. The great river of Harahovaiti flows into it from the Alborz, and from this sea, the two great rivers flow to the east and west and define the boundaries of the world $\stackrel{[10]}{ }$.

In the symbolic geography of religious traditions, mountains have an important value all around the world. The mountain is close to the sky and therefore has a dual sanctuary: on the one hand, it uses the symbol of space, such as the high and the vertical, and on the other hand, the domain of the manifestations of the sanctity of precipitation and is considered to be the residence of the gods. From many perspectives, the first mountains were raised after the storm and maybe after the initial turmoil. Some of the mountains, like the cosmic mountains, are located in the center of a world-wide 
universe, such as the Alborz, and others are places of revelation and intuition, or the home and the divine manifestation $\stackrel{[16]}{ }$.

Generally, mountains, hills and peaks are related to the idea of meditation, spiritual excellence and sharing with the holy rule ${ }^{[17]}$. In Islamic beliefs, the narratives say that many prophets' lives have been on the mountains. For example, Jabal al-Nour is the name of the mountain where the cave of Hara is located, and Prophet Muhammad (PBUH) was proclaimed as the prophet of Islam in this very cave. As in Mount Sinai that the Lord appeared to Moses by fire. It has been mentioned in the narratives that the miracle of Hazrat Salih (AS), came out of the form of a camel from the heart of the mountain. In popular culture, every city or village located near the mountain has an inseparable link with its myths and beliefs. After Islam, many religious elders and descendants of the Imams have been buried on top of the mountains alongside the sacred trees. The source of great rivers and clear springs lies in the heart of the mountains. And this has created a secretive and linkage of narrative between the ancient, religious, and folk beliefs of the land of Iran.

\subsection{Water, river, fountains}

Iran is a land with an arid climate, and its myths are full of rituals and narratives related to rain and rainy gods, and its reflection in the religious hymns of Persians has remained. There is a lot of talk about dread of draught in these hymns $\frac{[18]}{}$.

Therefore, looking again at the elements and characters of this narrative from a symbolic point of view and in relation to the element of water can open the way to the hidden truth behind this battle. The problem of water shortage is a serious environmental crisis in Iran. In particular, over the past decade, Iran has been severely affected by this crisis. The drying of lakes and rivers such as Lake Urumieh, Hamoon Lake, Zayandeh Rood, which is the origin of the formation of ancient civilizations with great cultures in the geography of Iran.

In Ancient Iran, Anahita or Arduivsuranhaita is the goddess of all the waters on Earth and the origin of the cosmic ocean. The chariot is pulled by four horses; winds, rain, clouds and snow. He is the source of life, the seed cleaner of all males and womb of all females, and the purifier of milk in the breast of all mothers. Because of its connection with life, warriors in battle ask her for survival and victory. Anahita appears in the pictures as a beautiful maid with a Barsom (stick) in her hands ${ }^{[10]}{ }^{[18]}$. The symbols that are reminiscent of Anahita due to their relationship with water are: lilium, fish, dolphin, duck, and also Sebu (pot), seen on dishes, objects and rocks of the Sassanid era.

The Tishtrya is another sacred face in the universe that relates to nature and rain; it is the good power that is involved in the awesome war against the monster of drought and destruction $\frac{[18]}{}$. Water is the origin of all creatures and the element of the first life not only for human beings, but also all beings, plants and animals. Water is the symbol of reason and wisdom. It has been said in Safine Albahar that in fact water is a liquid form of light. Because as science brings life to the soul, water also brings the life to the body ${ }^{[20]}$. In the Islamic beliefs of the waters, following the ancient Iranian beliefs that the goddess Anahita is the clerk of water, it belongs to the Zahra (sa), as his dowry was also water. One of the wish of the believers is drinking from the water 
of Kosar in Paradise ${ }^{[201}$. And the Qur'anic Surah is called Kowsar. In another tradition of Imam Baqir (AS) it is said: Hazrat Zahra's dowry in heaven is one fifth of the world and a third of Paradise and four rivers of the world; Euphrates, Neil, Nahravan and Balkh ${ }^{[22]}$. Water has a high status and is a symbol of purity in the traditions and Islamic tradition. In many cases, cleansing is only acceptable with water. In Islamic narrations, there are etiquette on how to drink water. In the hadith of Prophet Mohammad $(\mathrm{PBUH})$, water is introduced in the world and the hereafter as the best beverage ${ }^{[23]}$. In the Islamic tradition, for drought and the need for water for plants, agriculture and planting time, the farmers pray individually or in a group pray for rain.

\subsection{Vegetation; flowers, trees}

Among the creatures, plants have come in handy applications as sources of nutrition, treatment and industry. Different communities have native holy trees. Old trees that existed in the cemeteries and near the sanctuaries were chosen by the people and, in the ancient religious perception and experience, are the symbol of supernatural beliefs, as they are always spiritual in nature alongside the tree. A tree has never been worshiped as a tree itself, but they are mixed with mysteries and odd beliefs ${ }^{[21]}$.

In the myths of Zoroastrian creation, the first humane was Givmard (in the Kayumars Shahnameh), who lived in the west of the Sea of Farakhkert. He was killed by the devil and his sprout was purified by the sun. After forty years, Rhubarb plant has recovered from it, and gradually grew to become the first mortal man and woman. And from them, the human race continued. The narrative of this myth points out that there is a relationship between the human being's existence and the fertility and fruitfulness of the ancestors of mankind by the plants. In ancient times, plants like Humeh, Niloufar, Rosetta, Cedar, Plane and rye were of sacred nature, and sometimes they were named after a special god. "Hume", for example, is a god who gives health and strength, and blesses children's products. Hume is a supernatural herb that is an anthrax strain that has the ability to heal. It was believed that "Hume" would have the power to overcome any hostility.

Other myths have been combined with heroes and goodness and blessings on earth with herbs. The mother of all the trees that originated from all herbs was described in Kirst, and is described in Yasht $[12,17]$, the tree of Sein is described as the cure of all sorts of illness, or the tree of all the seeds. The legendary bird's nest (phoenix) was on this tree. The question of life and death is narrated both by the name of the variety of plants. The creation of man from rhubarb, the creation of a variety of plants from the tree of all the seeds, and the eternal life and in the other world are all called after the plants $\stackrel{[10]}{~}$ In Islam, the oldest tree in which the traditions of Islam and the religion of the creation of mankind are formed is a forbidden tree. "From Islamic view, plants, although they do not have the power of dignity and wisdom, but enjoy understanding and emotion. That is why, Islamic jurisprudence does not allow human beings to destroy plant life ${ }^{[24]}$. In Islamic times, there are also holy and symbolic plants such as the Touba tree and the Sardar al-Lamanth, two tall trees in the seventh heaven. Cypress, Plane and Buxus are planted in Iran's holy shrines and holy places. The images of the cedar in the interior and exterior of Islamic holy buildings in Iran can be seen repeatedly. 


\subsection{Animals}

Animals have always had a special place in Iranian culture and beliefs, and the use of animal drawings as a summary is one of the most characteristic features of Iranian art. These motifs have been seen in Iranian art from the cave period, and almost all artistic works have animal designs. During the various periods of time, the Iranian artist has mastered the animal's abstract visualization and has designed a variety of domestic animals, wildlife, birds and legendary animals in a magnificent way on different levels. The beliefs that Iranians have about different beasts has been the reason behind the design of these works for a variety of handicrafts.

According to mythological beliefs in the Zoroastrian tradition, the creation of animals is carried out in three distinct sections: quadrupeds walking on the ground, fish swimming in sea and birds flying in sky [25]. The cow has a special status in mythical views, among other animals, and according to the narrative of religious and mythological texts, it is the fifth creature of the Hormozd. The first beast of the world that was killed by the devil was the cow, and from his sprout, which went to the moon, animal species, and many plants have appeared. According to ancient Persians beliefs, the creation of all useful plants and animals originates from the creation of the first cow (Evedad). According to Mircea Elide, the universe does not create in the hands of the Lord, but by virtue of sacrificing a monster or a strange creature, created by a god 26$]$. By sacrificing this primitive beast other beings are created, is the very first cow in the belief of ancient Persians ${ }^{[27]}$. The tradition of painting the surfaces with animal designs continued in the Islamic era and was used in a variety of industries and arts. Several examples of these images can be found in the works of the past from different ages. These people lived alongside animals, hunted them, or hailed as sacred symbols. They used their role and form in their tools and objects, sometimes combining them and creating legendary animals such as phoenix. Many animals are like cock, lion, goat, snake, cow and fish, which were not only sacred in pre-Islamic beliefs. also enjoyed great importance among Iranians in another aspect after Islam, according to the philosophy of Islamic thought.

\subsection{Fire and light}

The word Atash (Fire), in the Avesta (Atar), in Pahlavi (Atur) and Atur and Atash in the Persian. In Yasn 21, paragraph 7 of Avesta says: "We worship Azar the son of Ahuramazda, the clean fire and the son of Ahuramazda and the purity, we worship all the fire" ${ }^{228}$. "Fire was the most important invention of human life. This element has long been considered by tribes among the four elements (water, wind, soil and fire). And in most Aryan religions it was a special privilege. In Iran, they attribute the emergence of fire to Hushang. The day of the emergence of fire to praise the birth of Forough Izadi (heavenly light), they celebrated that day in the name of the Feast of the Century ${ }^{[13]}$. The Iranians read the fire as a symbol of the god and its flames reminded of God's forgiveness, and they paid special respect to the flame of fire, which was the sanctuary of the followers of Mazdeysna and always kept the fire burning. One of the reasons for the respect for the fire was that they considered it a source of life like water. Because heat, as the essence of human life, is the sign of life in many beings, and coldness is the sign of death in creature especially humans and animals. Rumi also interprets the spiritual fire within plants and objects as follows: 
Love is a fire that caught the straw and the love appears in wine

The sound of straw is because of fire not wind, and anyone who does not have this fire, dies. (Masnavi: $1 / 10)$

The abstract and the essence of fire in the Avesta is called Far or Khoreh, and it is a bluish or majestic and special magnitude which is for Ahuramazda to be proclaimed as a prophet or a hero ${ }^{[13]}$. Avesta has enumerated five types of fire and praised each one: a great fire, known as the fire of Bahram in fire temples, the fire of the bodies of animals and the human body: instinct heat, vegetable fire and wood, fire of clouds: electricity or fire from the hammer of Toshtar, the fire in the eternal palace is in front of Hurmazda.

The Var Garm that Siavosh and others have been testing for is related to these types of fire tasks. The fire test is also mentioned in the story of Weiss and Ramin and the Tristan and Isolt. Perhaps that is why, during periods in ancient Iran, they burned the corpse: every one sat fire in various places, one because he was tired and the other one burnt a corpse (Gershaspamata: Asdi-Toosi).

The importance of fire is also well known in the ceremony of the Chaharshanbe Suri and the celebration of the Seddah ${ }^{[13]}$. "Among the Bedouin Arabs, the premonition of incandescence was prevalent at certain times. In the Holy Qur'an, the surah of Taha 11-12; and the Namal 3-7 (Fire = Nar) is also a blessing sent from the Lord and a manifestation of the Lord over Moses. ${ }^{[29] ~ “ . ~}$
The heavenly fire is the keeper of the life of the beasts and the fire of the earth is cleansing and burning filth and sin. Hence, in ancient Iran, they believed that at the end of the world, all human beings should pass through a fire, and the good and the bad will be rewarded ${ }^{[13]}$. A similar conception in Islam is due to the torment of sinners in the hereafter by fire, which is named "torment of the hereafter", and "fire of hell". According to the verses of Surah al-A'raf 12, Hajar 27, the Satan and the jinn are created of fire [29].

The significance of fire has affected the illumination philosophy as well. The philosophical language of Sheikh Ishraq is the language of symbols and illuminated metaphors. In the meantime, the word light has a special feature. Light and the word in front of that darkness, have great semantic capacity, has placed many of its external meanings and its credits in the official philosophy (Mashay); the meanings of existence, truth and reality in light, and the meanings of inexistence, possibility, nature and effects can be

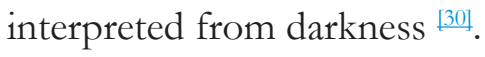

\section{DISCUSSION AND CONCLUSION}

One of the best solution to solve environmental issues is using rich symbols of local culture to return to historical and cultural traditions using their own ethnic and national language. Among the various symbols in the Iranian culture, there are symbols related to the elements of nature and the environment such as water and river, the moon and the sun and stars, mountains, trees, forests and various types of plants and animals. The study of symbols shows that the tendency toward immortality and the continuation of human life is directly linked to a variety of symbols from the creation of the 
universe to the challenges of life and death. Applying the symbols that roots in the beliefs of a nation can be used to teach and improve people's behavior toward nature.

The natural symbols are seen in Zoroastrian thoughts and even before that in myths and symbols that come from the intimidation and effects of heat and cold, wind and rain or drought and the need for food. There has been special attention to the great arches of the sky, the sun, the moon, animals, plants and other natural elements. The dependence of symbols on each other; sky, wind, rain, river, land, flood, fire, light, plants and animals, each of which is intertwined with myths and symbols in some way, it illustrates the connected flow which today can be termed as an environmental cycle. The continuity and solidarity of symbols, beliefs and rituals, celebrations, commemoration, holiness, and sacraments are all because of respect, need, fear and hope. Human can reach unity by supposing the deep relation between human and environment as their only savior. Assuming that human is a part of nature, plants, water, river, soil, air and animals can be understood in different ways. Not polluting the water and soil and environment, since a large percentage of environmental pollution is caused by urban waste and industrial units annually. Setting fire on forests, cutting forest trees for various local and industrial uses, degradation of mountains (considered as nails of earth), with all the greatness and sanctity of the space where their disappearance caused extensive experience in the way of life of other living organisms, which disrupts the ratio of air humidity and similar problems in that region.

Zoroastrian and Islamic culture has a valuable treasure of ancient beliefs that can be applied to survive the nature and environment.

\section{REFERENCES}

1. Mohammadzadeh, R. "The study of the status of nature in modernity and face-to-face challenges with emphasis on Iranian cities", Geography and Urban Planning, Vol. 18, No. 48, pp. 245-278, 2013

2. Fouladi M., Hassanpour M., "The Role of Symbol and Symbolism in Human Life, A Sociological Analysis", Social Cultural Knowledge, Year 6, No. 4, Successive 24, Pages: 133-152, 2015.

3. Tufiqi, h. Familiarity with the Great Religions, SAMT Pub, 2012.

4. Rul Alamini, M. Cultural and social phenomena in Persian literature, Agah publication, 2000.

5. Farahvashi, B. Yashtha, Volume 1 \& 2, Tehran University Press, 1977.

6. Loneliness, h. Sociology in Religions, Behabad Publication, 1994.

7. Javadi-Ameli, A "The environmental culture is blended with the superior position of God's succession," the International Conference on the Environment, Religion and Culture, 2001.

8. Akbari Rad, Tayebeh. "The Role of Islamic Teaching in Reducing Environmental Crises," Environmental Journal, Vol. 39, No. 1, pp. 73-80, 2013.

9. Mohaqeq Damad, M. Nature and the Environment of Man from the Viewpoint of Islam, Rahnemoun Publishing, 1992.

10.Sarkhosh Curtis. Iranian mythology, Translator: Abbas Mokhber, Markaz Pub, 2009.

11. Kumen, F. Mithraism mystery ritual, Translator: Hashem Razi, Behjat Publishing House, 2004.

12. Bahar, M. Research in Iranian mythology, Agah Publishing House, 1996.

13. Yahaqi, M. Culture of mythology and storytelling in Persian literature, Farhang-e Mo'asere publication, 2007.

14. Hejazi, M. "Symbols of the Gravestones of Sefid Chah Cemetery ", The first national conference of the art of Tabarestan, Pages: 49-37, 2012.

15. Razaghi, A. Quranic Oaths, Publisher of Imam Sadiq Institute of Education and Research, 2004.

16. Mei, Y.P "Mountains", Encyclopedia of Religion, Mircea Eliade (ed.), vol.14, MacMillan Reference Books, New York, 1987. 
17. Sirlo, h. Dictionary of Symbols, Mehrangiz Oohadi, Dastan pub, 2013.

18. Hilens, J. Iranian Myth, Mahnaz Shayestehfar, Islamic Institute of Publications, 2009.

19. Crimson, Roman. Iran from the Beginning of Islam, Translator: Mohammad Moein, Science and Culture Publishing, 1989.

20.Qomi, Sh. Al-Bohar and Madinah al-Hakam and Al-Isar, Volume 2, Islamic Publications Office, 1999.

21.Javadi, Sh. "Reviewing the ancient narrative" Water and Tree "during the Islamic era of Iran," East Art and Civilization, First Year, No. 1, Pages: 43-50, 2013.

22. Rasulli Mahallati, S. The Life of Hazrat Fatemeh (S), Office of the Publishing of Islamic Culture, Tehran, 2002.

23.Nouri, Mirza Hussein. Mustardak al-Sousil, Volume 3, Al-Alibat Institute, 1408 AH.

24. Karami, M., Naghizadeh, H. "Infrastructure of Plant Rights from the Quranic Perspective", Journal of Islamic Traditional Medicine and Iran, Vol. 5, No. 1, pp. 61-67, 2014.

25.Rashed Mousal, M. Translated by Zad Sperm, Cultural Studies and Research Institute, 1987.

26.Eliadeh, M. Treatise on the History of the Religions, Translator: Jalal Sattari, Soroush Publication, 1993.

27.Hosseini Kazerouni, S., Motevaseli, N., Nadafi, M., "Goshorun (Anthology and Mythological Review in Ferdowsi's Shahnameh"), Quarterly Journal of Educational and Enrichment Studies of Persian Language and Literature, Islamic Azad University, Bushehr Branch, No. Successive 28, 31-44, 2016.
28.Purdavood, A. Yasna, Rushdie Pub, 1961.

29.Habibi, p. "Fire and the symbolism of religious and literary mythology in Hafez's sonnets", 6th National Conference on Literary Research, Persian Literature Society of Shahid Beheshti University, 2012.

30.Seyed Mohammad Ali Dibaji (2011), "The Status of Light in the Illumination Philosophy", Religious Thought Quarterly, Shiraz University. 39, p. 3. 